\title{
Portrait of the Profession According to Millennials
}

Reproduced in English from the original article in Vol. 41, No. 2 of "L'Optométriste".

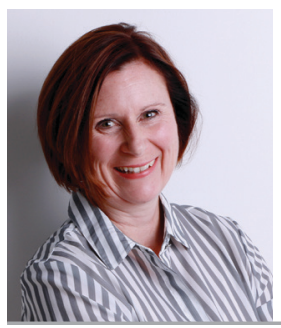

Claudine Lussier MBA, is the author of the labour and management column for the journal L'Optométriste published by the Association des optométristes du Québec, where she has been working for about 15 years. Ms. Lussier designed and established the training program for optometry assistants.

he Optometric Leaders Forum (OLF), held in late January, is THE annual gathering of leaders from associations, provincial associations and Canadian schools of optometry. It is a good opportunity for taking stock of the current practice and identifying emerging trends. In order to obtain a snapshot of the situation, the Canadian Association of Optometrists (CAO) conducted two surveys. One was done among optometry students from the Montreal and Waterloo schools, and the other was done among young optometrists from 2013 to 2017 . The respondents were therefore millennials aged 21 to 37 . We compare students' ideals to the reality of young graduates in a context of full employment.

First, what influences the decision of students and young optometrists when the time comes to choose a practice location?

For students, just over one quarter (26.86\%) believe that salary is the most important factor in choosing a workplace during the first five years of practice. ${ }^{1}$ Those same students believe that lifestyle is one of the determinants in choosing a workplace $(63.87 \%)$ after 15 years of practice.

For young optometrists, the two main influencing factors are family, for $70.7 \%$ of respondents, and potential income, for $59.1 \%$ of them. ${ }^{2}$ As for lifestyle, although it came in fourth, it is still a decision factor for young optometrists (ranging from $63.87 \%$ to $36.6 \%$ ).

After one or two years of experience, young optometrists reassess their situation, as do most millennials. They think about aspects of the practice that are slightly different from those that had influenced their previous decisions. As such, compensation is still a priority for 36\% of them (versus 59.1\% upon hiring). Lifestyle (23\%) and work schedules (16\%) are considerations as well, no doubt in connection with family. Therefore, these priorities are retention aspects that clinic leaders will have to negotiate.

Recruiting challenges in regions far from major urban centres appear to be the same across Canada. Students from the schools of optometry were asked about this. When asked "Would you be willing to settle in a remote area?" $9 \%$ of respondents indicated that they would practice and stay in a remote area because they were born there or were already planning to live there. However, $18 \%$ of students would refuse to settle there. In between, some students would accept a one-year (19\%) or a two-year (27\%) contract in a remote area.

Then, we know that in Quebec, 85.5\% of optometrists under the age of 35 have self-employed-worker status, and most of them work in multiple optometry clinics. ${ }^{3}$ This picture is similar to what it is for Canada as a whole: $33.5 \%$ of young graduates responding to the survey work in a single clinic; $38.1 \%$ work in two clinics; and $28.4 \%$ work in more than two clinics.

For half the respondents (53\%), a work week has five days (between 31 and 40 hours per week); whereas $20 \%$ of respondents work less than five days per week (between 10 and 30 hours) and 30\% work up to seven days per week (between 41 and 60 hours). As a reference point, we refer to the latest survey on the practice, which found that optometrists in Quebec work an average of 30.8 hours per week in clinics. 
This doesn't entirely align with the ideal of the optometry students who participated in the CAO's survey: working in a single clinic (51\%) or two different clinics (41\%). The most realistic ones believe that they will have to work in several clinics in order to have a full workload. Most students also believe that working in multiple clinics for one or two years will enable them to learn much more about the optometry practice.

In general, young optometrists say they are very satisfied with their work and their career development and give it a score of 4.3 out of 5 . Just over half of young optometrists and students (55\%) want to become the owner of or partner in an optometry clinic within ten years or so.

The priorities of young millennial optometrists change as the choices in their personal and professional lives change. As such, they will have to review their short- and long-term ambitions when negotiating their employment contract, during their hiring interview and upon leaving. As for students' ideals, will they align with the reality of the practice once they enter the labour market? Or will the market adapt to their requirements? Only time will tell. $\bullet$

SUMMARY PORTRAIT OF THE PROFESSION ACCORDING TO MILLENNIALS

$53 \%$ of young optometrists work 5 days per week, i.e. between 31 and 40 hours.

$66.5 \%$ of young optometrists work in two or more clinics.

$59.1 \%$ of young optometrists say that compensation is a priority.

$27 \%$ of optometry students would be willing to practice in a region far from major urban centres for two years.

55\% of students and young optometrists want to become a partner in or owner of a clinic.

$86 \%$ of young optometrists are satisfied with their job.

\section{FOOTNOTES}

${ }^{1} 310$ students responded to the CAO’s survey.

${ }^{2} 215$ new graduates responded to the CAO survey.

${ }^{3}$ Optometric practice survey, 2017.

\section{REFERENCES:}

Zinc Beauchesne and Associates, Optometric practice survey, Association des optométristes du Québec, June 2017

Yuen, Abraham, BSc, OD, Canadian Optometry Graduate Workforce Report, Canadian Association of Optometrists, January 2019

Nguyen, Wynn; So, Raphaela; Yau, Quinton; Tran, Jennifer, 2019 CAOS SEE Survey Report, Canadian Association of Optometry Students, January 2019 